Research, part of a Special Feature on Making Sense of Climate Change, Orientations to Adaptation

\title{
Sensemaking: a complexity perspective
}

\author{
Timothy Lynam $^{1,2,3}$ and Chris Fletcher ${ }^{4}$
}

ABSTRACT. Our intent was to provide a methodological overview of the primary data collection process in support of the other articles in this special issue. We documented and illustrated the use of a data collection and analysis suite, SenseMaker, that was designed to collect and work with narrative fragments. The approach presented adds a new and inherently mixed tool to the mixed methods toolbox. Despite its novelty and potential utility, little has been written in the academic literature on the application of SenseMaker to complex problems. To the best of our knowledge, the approach has not been used in relation to climate change or climate change adaptation and has not been presented in the mixed methods literature. We sought to contribute to filling this gap through describing the approach used to generate the data that underpin the articles in this special feature. Our purpose was to illustrate some of the potential and most notable challenges of using the SenseMaker data collection and analysis process in a complex domain through examining adaptation to climate change. Our overview was not exhaustive but rather sought to highlight capabilities and challenges through examining experiences of adaptation from a stages of change perspective. SenseMaker provides a remarkably powerful tool for the capture of micronarratives of complex phenomena such as climate change. The capacity to have respondents interpret, i.e., make sense of, their own narratives is an important innovation that provides one plausible solution to the problem of analysts coding narratives. Analytically, however, SenseMaker is relatively weak for those seeking strong statistical support for analyses and provides no capability for analyzing the narratives themselves.

Key Words: adaptation; climate change; complexity; micronarratives; mixed methods approach; narratives; sensemaking; stages of change (SOC); transtheoretical model

\section{INTRODUCTION}

Climate change, we are told, is a dramatic example of a complex or wicked problem (Australian Public Services Commission 2007b, Lazarus 2009, Levin et al. 2012). With this class of problem, we should not expect clear resolution but rather negotiated compromise among the positions advocated by different social groups that will most often have different perspectives on the nature of the problem and what actions to take (Australian Public Services Commission 2007b, Noble and Bennett 2007, Milne 2015). At the same time, climate change is an emerging problem, one that is new to many people, nuanced, contested, uncertain, and in flux (Lorenzoni and Pidgeon 2006, Lorenzoni et al. 2006, Lorenzoni and Hulme 2009). The positions and orientations of different social actors, i.e., their representations, are not fixed but are continuously created, modified, discussed, reproduced, and enacted through everyday discourse and action (Wagner and Hayes 2005).

Complexity theory provides a potentially useful orientation to understanding and then acting within the emergent flux of representations, positions, and actions to achieve desirable social outcomes in relation to climate change adaptation (Australian Public Services Commission 2007b, Milne 2015). However, to work with this sort of complex system, we need to capture snapshots of the experiences, conversations, utterances, or associations of actors within it as they shift, chimera-like, through time or among different social groups. We need to be able to analyze these elements of emerging representations rapidly and, through so doing, identify patterns that flag where interventions might be most effective to enhance effective adaptation or dampen maladaptation. How do we do this? How can we capture people's conversations around their experiences of climate change adaptation and analyze these to identify useful patterns? Are there patterns in the factors associated with adaptation across different types of adaptation or across different social groups? How do we analyze people's experiences and conversations about their experiences without imposing our own frames of reference on the conversations and hence imprinting our own frames on what we find?

This quote from our survey of people's experiences of what enabled and what constrained adaptation to climate change highlights many of the points we seek to make: "Complexity, the overwhelming nature of it all, the inability to associate individual action with the greater good (just another 'Tragedy of the Commons'), inability to distinguish good information from bad, lack of bipartisan political support" (Victorian State government Department of Sustainability and Environment [DSE] Survey, October and November 2010). First, the fragment illustrates that perceptions of complexity are contextual and depend on the perspective of the speaker (Manson 2001). The social roles from which people view situations or speak are an important contributor to, and source of information about, making sense of or in complex situations.

A second point this fragment illustrates is a feeling of being overwhelmed, of being out of control, which, as an important consequence of complexity, is a discomforting condition for many people (Cacioppo and Petty 1982, Webster and Kruglanski 1994, Cacioppo et al. 1996). People's judgment of their ability to "organize and execute courses of action" is an important determinant of their success: people who believe they can achieve something are more likely to achieve it than those who doubt their ability even when we take their actual ability into account (Bandura 1986:391). Being overwhelmed or out of control implies a sense of helplessness, a low self-efficacy appraisal, and hence a tendency to inaction or to take the easy route of doing what one has always done. 
A third point the fragment illustrates is that multiple perspectives are not only possible but the norm in complex situations. Multiple perspectives result in people finding it difficult to "distinguish good information from bad" and hence achieve clarity (DSE Survey, October and November 2010). In addition, causality or the effectiveness of solutions is seldom clear (Kurtz and Snowden 2003, Snowden and Boone 2007), resulting in an "inability to associate individual action with the greater good" (DSE Survey, October and November 2010). Despite this lack of clarity on causality and solutions, people very often define complex problems in relation to solutions (Rittel and Webber 1973), i.e., "just another "Tragedy of the Commons," predisposing them to particular solutions and hence limiting the search for others. Multiple perspectives create the potential for good, in the form of the potential for the emergence of creative solutions for wicked problems (Brown et al. 2010), or ill, such as when polarization of perspectives results in distorted representations and increased separation of positions and, consequently, makes solving the problem that much more difficult (Bovens and 't Hart 1996, Oreskes and Conway 2010).

Not all problems require multiple perspectives approaches. David Snowden and colleagues (Snowden 2002, Kurtz and Snowden 2003, Snowden and Boone 2007) posit five domains of societal or organizational knowledge: the simple domain, where causeeffect relationships are known and the task of managers is simply to categorize a phenomenon and then apply the rules pertinent to that category; the complicated domain, where cause-effect relationships are discernible, but because competing explanations or action sets are likely, discerning the best course of action requires expert knowledge and interpretation; the complex domain, where cause-effect relationships are only retrospectively discernible and may not repeat themselves, thus requiring examination of patterns and thence deft probing to experimentally test potential actions; the chaotic domain, where no cause-effect relationships are discernible and action to stabilize the situation is the best course of action; and the domain of disorder, in which we do not know within which domain the phenomenon resides.

Multiple perspectives are not relevant in the simple domain and have little relevance in the chaotic domain. In the simple domain, the problem and solutions are self-evident as noted by a respondent in our survey: "There are many simple ways to make changes that impact climate change and if we each do the simple things we will be contributing to a better earth that our grandchildren will be able to enjoy" (DSE Survey, October and November 2010). Multiple perspectives are pertinent in the complicated domain. Through applying expert knowledge and scientific methods, society can identify, if not the best, at least good strategies of action. For example, challenging competing explanatory models with data and then using the best model for prediction and action strategy development is one approach, or the use of ensembles of models as is increasingly advocated in climate change research is another (Räisänen and Palmer 2001, Burnham and Anderson 2002, Reichler and Kim 2008, Pierce et al. 2009). We acknowledge that despite the availability of these approaches, as well as a number of others, for application to problems in the complicated domain, knowledge, data, models, or interpretations are often contested.
It is when we consider phenomena in the complex domain that multiple perspectives dominate the conceptual stage. It would be difficult to articulate this more clearly than did Edelman (1988:12), as follows:

Problems come into discourse and therefore into existence as reinforcements of ideologies, not simply because they are there or because they are important for wellbeing. They signify who are virtuous and useful and who are dangerous or inadequate, which actions will be rewarded and which penalized. They constitute people as subjects with particular kinds of aspirations, selfconcepts, and fears, and they create beliefs about the relative importance of events and objects. They are critical in determining who exercise authority and who accept it. They construct areas of immunity from concern because those areas are not seen as problems. Like leaders and enemies, they define the contours of the social world, not in the same way for everyone, but in the light of the diverse situations from which people respond to the political spectacle.

The absence of repeatable cause-effect relationships places phenomena of the complex domain beyond the purview of normal science that relies heavily on stable and repeatable causeeffect relationships. Instead, we find ourselves in the realm of postnormal science or the science of wicked problems where the who and the why and the how of problem or solution construction or framing become critical to analysis and to action (Rittel and Webber 1973, Funtowicz and Ravetz 1994, Ravetz 2004, Healy 2011). To explore and comprehend the different perspectives, the different actors, and the different framings of what the problem is or is not and how to solve it, researchers investigating problems in this domain require richer data sets, data sets that enable us to examine situations from some of the different perspectives that contribute to creating and maintaining the situational complexity.

Across many areas of social research, narrative has been identified as an important data source for understanding human experience in all its complexity and richness (Barthes 1977, Weick 1995, Czarniawska 1997, 2002, Franzosi 1998, Clandinin and Connelly 2000). "Narrative is a vital human activity which structures experience and gives it meaning"; it "is a way of knowing" that "assist[s] humans to make life experiences meaningful" (Kramp 2004:104, 107). Narrative is a universally important sensemaking device for people that "is present in every age, in every place, in every society ... it is simply there, like life itself ..." (Barthes 1977:79). The analysis of narrative is difficult and timeconsuming when using the traditional tools of narrative analysis: interpreting and thence coding fragments of narratives and then analyzing the frequencies of these codes. For those seeking to analyze interpreted micronarratives, SenseMaker neatly circumvents this step through having respondents use the measures in the instrument to interpret their own narrative. SenseMaker offers a data collection process and some analytical capabilities for working with micronarratives that are new and largely untested. It sits between quantitative survey tools and open-ended narrative.

Although not without critics (Sandelowski 2014), mixed methods approaches are frequently cited as being well suited to complex 
problems (Johnson and Onwuegbuzie 2004, Teddlie and Tashakkori 2009, Mertens 2010). These approaches have been hailed as bridging the two sides in the so-called paradigmatic wars between constructivist/qualitative and positivist/quantitative research paradigms (Teddlie and Tashakkori 2009). Among advocates of the mixed methods approach, there has been much discussion around the sequencing and relative dominance of the qualitative and quantitative research stages, which are seen as linked but separate data collection phases (Tashakkori and Teddlie 2003, Johnson and Onwuegbuzie 2004, Mertens 2010, Tashakkori and Teddlie 2010), or the difficulty of integrating the data arising from these two data collection activities (Greene 2008, Bazeley 2012, Fielding 2012). There has been less discussion or examination, however, on what have been called "inherently mixed" data sources (Teddlie and Tashakkori 2009) where qualitative and quantitative data are fundamentally mixed and integrated.

Our primary purpose is to document and illustrate the use of a data collection and analysis suite that has been designed to collect and work with "inherently mixed" data. David Snowden and colleagues developed an integrated set of data collection and analytical tools, i.e., SenseMaker, based on narrative, to support action-oriented inquiry in complex systems (Kurtz and Snowden 2003, Snowden and Boone 2007). Despite its novelty and potential utility, little has been written in the academic literature on the application of the SenseMaker suite of tools to complex problems. To the best of our knowledge, the approach has not been used in relation to climate change or climate change adaptation. We seek to contribute to filling this gap through describing the approach used to generate the data that underpin the articles in this special feature. Our purpose is to illustrate some of the potential and some of the most notable challenges of using the SenseMaker data collection and analysis process in a complex domain through examining adaptation to climate change. Our overview is not exhaustive but rather seeks to highlight capabilities and challenges by focusing on what the data tell us about how we might act to support greater adaptation to climate change. In addition, we provide a methodological overview of the primary data collection process in support of the other articles in this special issue.

The transtheoretical model of behavioral change originally developed by James Prochaska and colleagues in relation to drug dependency (Prochaska and DiClemente 1986, Prochaska et al. 1992) has been widely adopted but critiqued as lacking in supporting evidence (Sutton 2001, Armitage 2009); however, its use has been supported by the Australian Public Services Commission. The model recognizes four stages in people's journeys of change: (1) The precontemplation phase is the stage in which people are not yet ready to admit to the need for change. (2) The contemplative and preparatory stage is the stage in which people are considering and preparing for change. More recently, Prochaska and colleagues have separated contemplation and preparation, but we keep them combined for simplicity for our purpose. (3) The action stage is the stage in which people are actually changing. (4) Finally, the maintenance stage is the stage in which people are maintaining their modified behaviors. Prochaska and colleagues clearly identified the need to tailor processes designed to support change to each of these stages of change (SOC). This model may be usefully applied to wicked problems such as climate change (Australian Public Services
Commission 2007a, $b$ ). We use it as a framework for examining the SenseMaker narratives of adaptation to climate change.

In Methods, instrument, and data, we describe the instrument that was developed for data collection and provide a brief overview of the data that were collected and used as the primary data source for most articles in this special feature. We present examples of results through examining options to act to increase the likelihood of people being prepared for climate change. Finally, we describe some of the major challenges we faced in using this approach, as well as some of the opportunities for extension of the SenseMaker-based approach in relation to addressing complex problems such as adaptation to climate change.

\section{METHODS, INSTRUMENT, AND DATA}

SenseMaker is a commercial software package produced by Cognitive Edge (Cognitive Edge 2010). SenseMaker V2.5 was selected as a data collection tool for this project for three primary reasons: first, its ability to work with narrative; second, the ability to have respondents interpret, i.e., signify, their own narrative with these interpretations themselves being analyzable; and third, because it facilitated direct data capture through being an online instrument.

In essence, SenseMaker comprises two components: a set of data collection tools and a set of data analysis tools. SenseMaker instruments typically involve five tasks: a narrative in response to a prompting question; a series of multiple-choice questions about the narrative; a series of triadic and polarity measures associated with the narrative; a series of general research questions that are not linked to the narrative; and socio-demographic measures of the respondent (Online Resource 1). In our instrument, we added a set of three word-association tasks and did not use the general research questions task (Online Resource 1). A SenseMaker instrument seeks to situate respondents in an experience they have had, seen, or heard about and that relates to the field of interest, in our case, adaptation to climate change. The instrument then seeks to have respondents write a mininarrative of that experience and, through so doing, bring the experience into working memory. Respondents are then asked to interpret their narrative using a set of measures. Finally, the instrument may seek answers from respondents on questions not necessarily directly related to the experience and also elicits socio-demographic information from them.

With the exception of triadic and polarity measures, the instrument tasks are likely to be familiar to most readers. Triads present respondents with a three-dimensional scale. Respondents are typically asked to place a ball, i.e., mouse click or mark in paper-based versions, at the location in the triangular scale that matches the relationship of the three factors in their narrative (Online Resource 1). Polarities reflect scales that range from the complete absence of a factor on one end to an excess of that factor on the other. Again, respondents are asked to place a ball, i.e., mouse click, where they saw their narrative experience fitting on this continuum (see examples in Online Resource 1). No actual scale was visible to the respondents with either triads or polarities, and they could not see the numerical value associated with where they positioned the ball.

Analytically, SenseMaker provides a number of tools to explore and examine the data collected using a SenseMaker instrument. 
All of these tools facilitate the user to easily shift between identifying patterns in any of the measures associated with the narratives and the narratives themselves. Using a simple graphical user interface, SenseMaker provides tools to look at distributions of multiple-choice, polarity, and triadic questions as well as simple statistical analyses of these, i.e., correlations and t tests, and threedimensional modelling. From most of these tools, the user can easily select points on a plot and immediately examine the narratives associated with these points.

The instrument was applied on three separate occasions. In the first application (June/July 2010), respondents were participants at a scientific conference on climate change and adaptation $(\mathrm{n}=$ 193). The second application, administered in October and November 2010, was with the Victorian State government Department of Sustainability and Environment $(n=121)$. The final application (in April 2010, $\mathrm{n}=627$ ) captured responses from members of the public living in coastal regions of the eastern and southern seaboard of Australia and also from Canadian practitioners working on climate change and adaptation. The total across all applications was 940 valid responses. Respondents were randomly assigned $(p=0.5)$ to one of two instruments with the only difference between instruments being the presence of the word-association tasks in one and their absence in the other (Online Resource 1).

Almost exactly $50 \%$ of respondents were women and $50 \%$ were men, but the age distribution within each gender differed with women tending to be in younger age groups and men in older age groups (Online Resource 1). Thirty seven percent of the respondents identified themselves as being members of the general public, $27 \%$ identified themselves as being government employees, and 19\% identified themselves as scientists, academics, or researchers (Table 1).

Table 1. Count of responses by self-identified role.

\begin{tabular}{lc}
\hline \hline Self-identified role / social position of respondent & $\begin{array}{c}\text { Number of } \\
\text { responses }\end{array}$ \\
\hline General public / Community member / Rural or urban & 399 \\
resident & 161 \\
Other than these & 154 \\
Government agency employee & 113 \\
Scientist / Academic / Researcher & 77 \\
Community representative / NGO & 32 \\
Private sector employee & 4 \\
Media representative & 940 \\
Total usable responses &
\end{tabular}

\section{RESULTS}

Acknowledging that SenseMaker is designed to support action, we focus our explorations on identifying what actions could be taken to enhance the likelihood that people would adapt to climate change. We adopt the perspective of a social group, such as a government agency or a nongovernmental organization, that seeks to enhance the likelihood of adaptation. The SOC model forms the focus of our examinations. The small size and nonrepresentativeness of the sample suggest caution in extrapolating the results we present. However, the sample enables exploration and illustration of the application of SenseMaker to a specific issue.
Survey respondents were asked to respond to the following prompt (for full instrument, see Online Resource 1):

Imagine you are in a lift (elevator) with 2 people who
are discussing how people and institutions are reacting
to climate change. One person mentions that several
obstacles constrain the extent to which people are able to
prepare for impacts and or adapt. The other person says
that she knows of a few examples in which people and
institutions are already responding. They turn to you and
ask for your perspective on what makes preparation/
reaction possible or difficult. How would you respond?

Once they had typed their response into the text box provided, respondents were asked questions about their response. One of these related to how the experience they described related to change. We used the results of this question to identify positions on the SOC model (Table 2). Almost $60 \%$ of the sample identified their experiences as related to changing, i.e., action, or to reinforcing or magnifying change, i.e., maintenance.

Table 2. Relationships between the instrument measures and the stages of change (SOC) model. Respondents could select as many of the SOC categories as they liked, so the total is greater than the number of responses $(n=940)$, and the total percentage exceeds 100 .

\begin{tabular}{lccc}
\hline \hline Survey measure & Stage of change & $\begin{array}{c}\text { Number of } \\
\text { respondents } \\
\text { selecting }\end{array}$ & $\begin{array}{c}\text { Percent of } \\
\text { respondents }\end{array}$ \\
\hline $\begin{array}{l}\text { None of these } \\
\text { Getting ready for } \\
\text { change }\end{array}$ & $\begin{array}{c}\text { Precontemplation } \\
\text { Contemplation } \\
\text { and Preparation }\end{array}$ & 132 & 14 \\
$\begin{array}{l}\text { Changing } \\
\text { Reinforcing change, }\end{array}$ & Maintenance & 300 & 51 \\
magnifying change & 216 & 32 \\
TOTAL & & 1131 & 120 \\
\hline
\end{tabular}

In his social cognitive theory, Bandura (1986) identifies selfefficacy, i.e., a measure of a person's belief in his or her ability to achieve specific goals, as an important determinant of behavior and behavioral intention. Ajzen (1996) identified efficacy, i.e., perceived behavioral control, as a major determinant of behavioral intention, which was itself the best predictor of behavior. Prochaska and colleagues identified a strong relationship between self-efficacy and changes in addictive behaviors with self-efficacy changing through the SOC model (DiClemente and Prochaska 1982, Prochaska and DiClemente 1986). Our survey measurement of efficacy ranged, on a 100-point scale, from "Overwhelmed with opportunities to make a difference" $(=0)$ to "Unable to make a difference" $(=100)$. We use this efficacy variable as a focal variable for our investigations of how best to improve adaptation to climate change. The efficacy polarity data were not normally distributed: they were bound between 0 and 100, and they exhibited strong negative skews (see Appendix 1). In the analyses that follow, we use an estimate of the difference in means of the efficacy variable based on Markov chain Monte Carlo modelling (Gelman et al. 1995). Details of the modelling process and results are presented in Appendix 1, and the summary results are presented in Figures 1 and 2. 
Fig. 1. Distribution of estimates of the means of the efficacy polarity measure for individuals or groups in each stage of change. Median values are shown as a vertical red dashed line and also printed below the panel labels. HDI = highest density interval; in this instance, the $95 \%$ HDI is the range in which $95 \%$ of the probability mass was found. Values derived from Markov chain Monte Carlo modelling with details in Appendix 1.
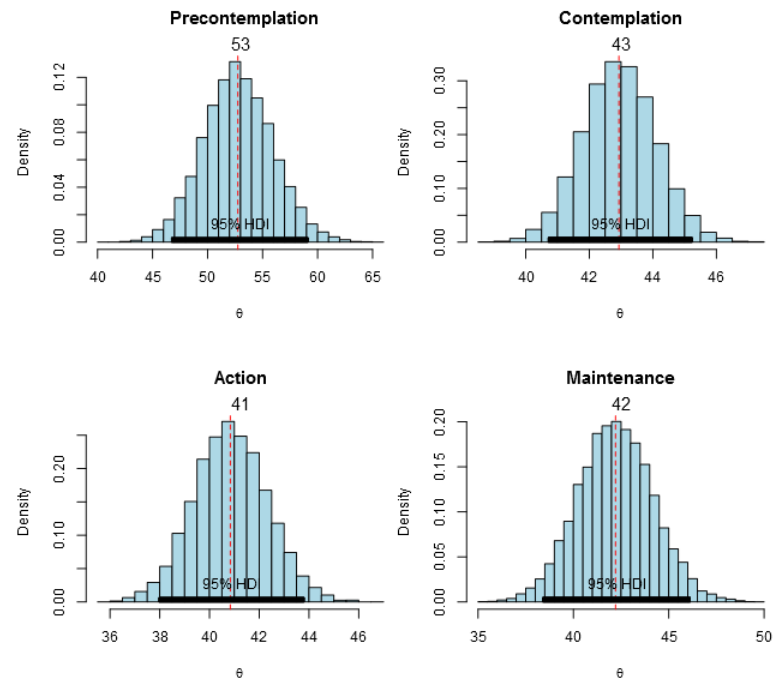

Fig. 2. Distribution of estimates of the differences between means of efficacy measure for response associated with each stage of change. Values derived from Markov chain Monte Carlo modelling with details in Appendix 1. As a rough guide, where the red dashed line of zero difference falls outside the $95 \%$ HDI, we can be $95 \%$ confident that the difference between means does not equal 0 . HDI $=$ highest density interval.
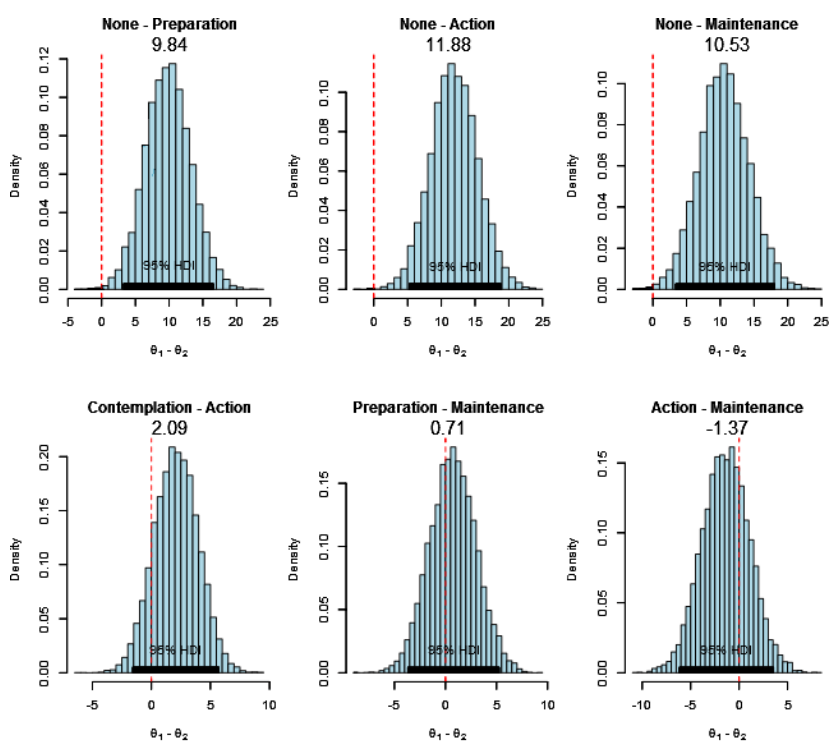

Overall, from the perspective of respondents who related experiences associated with the precontemplation stage, the individuals or groups in these experiences had lower efficacy, i.e., were less able to make a difference, than those whose perspective was of experiences of contemplative, action, or maintenance stages (Fig. 2). Threads in the narratives were identified using a mixture of three methods: first, using SenseMaker's browse function to select only those experiences associated with each of the SOC and reading through each of these narratives; second, using the search function on this set of responses to search for narratives containing particular terms; and third, visually inspecting plots of the signifiers using SenseMaker's plotting capabilities and then reading the narratives associated with patterns of signifiers in the plots (see Figs. 2, 3, and 4 for examples).

Fig. 3. Narrative signifiers for precontemplation stage narratives $(n=93)$. Top left, factors helping; top right, factors hindering; bottom left, extent that following played a role; bottom right, how important were the following.
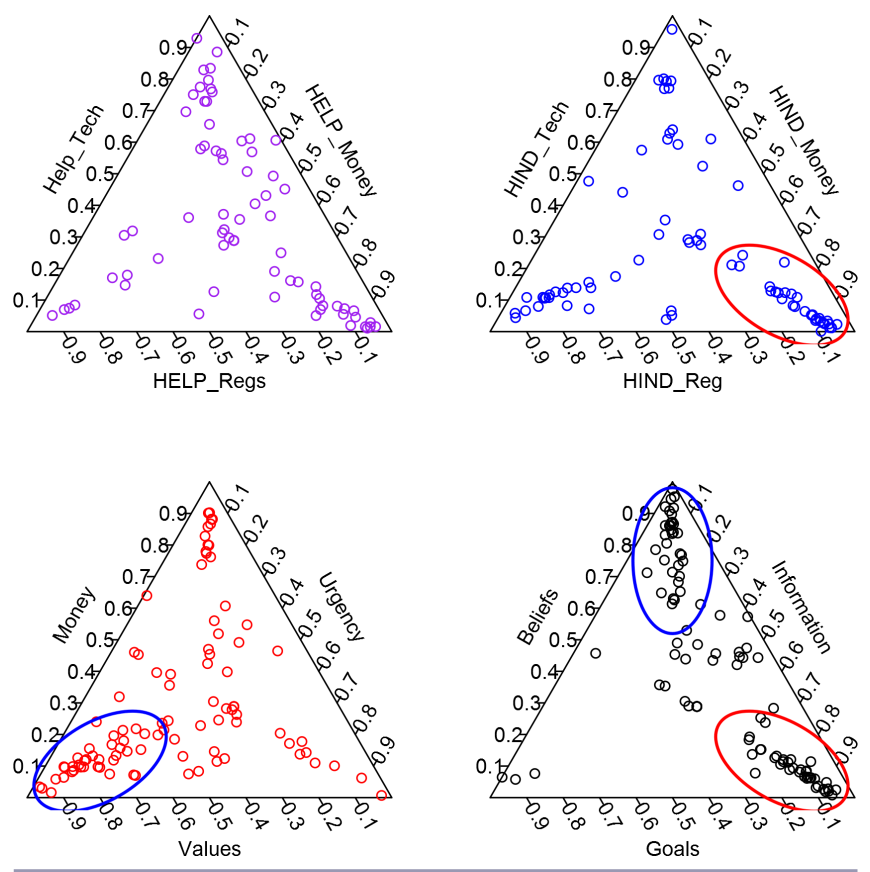

Precontemplation stage: preventing change

Four threads emerged in our examination of the narratives and the signification of the narratives by those in the precontemplation stage. These may be thought of as threads in the narratives of those not yet contemplating change. The first thread related to climate change being a global issue that was bigger than us so that there was little point in individuals doing anything: "I dont $[s i c]$ know why they are trying so hard when the main offenders in the world, China, India and USA to name a few are doing very little. Why should Australia which is a speck on the global map thump its chest by trying to prove a point" (Australian general public and Nova Scotia practitioners [AUS_NS] Survey, April 2011). 
Fig. 4. Narrative signifiers for contemplation stage narratives (n = 415). Top left, factors helping; top right, factors hindering; bottom left, extent that following played a role; bottom right, how important were the following.
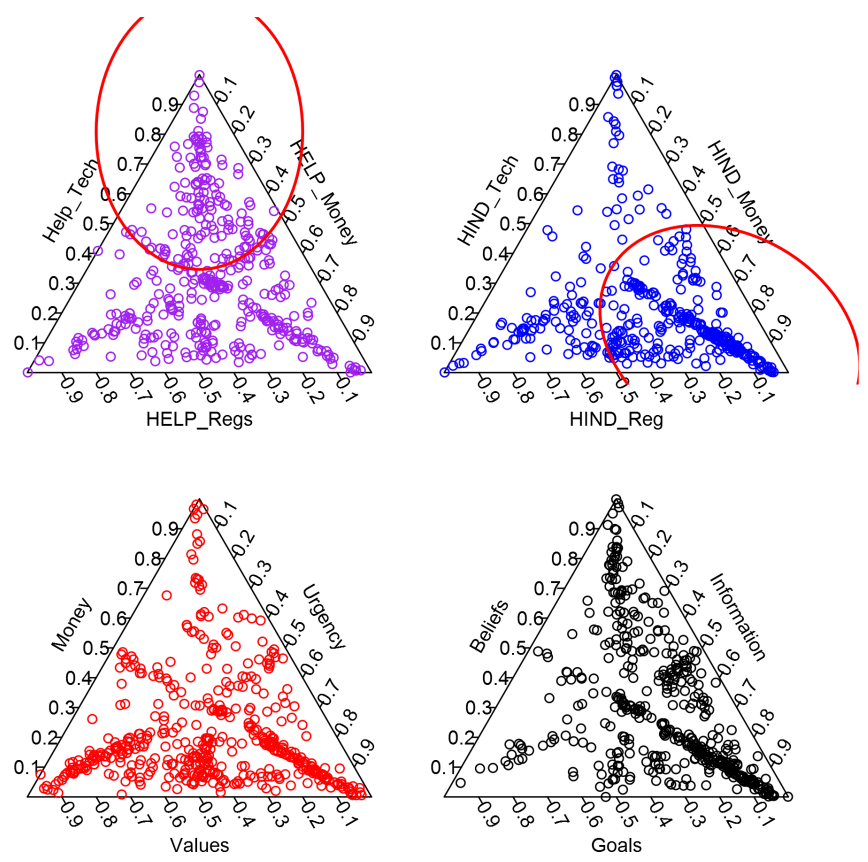

The second thread was associated with climate change denial and distrust of its proponents (Fig. 3, bottom left panel and bottom right, red ellipse): "Look at the way the numbers of scientists were reduced in evaluating climate change reports before the final one was released; all who disagreed with any findings never saw the next draft until only those who agreed with the wanted result were left" (AUS_NS Survey, April 2011).

The third thread related to the costs of adaptation being perceived to be high or out of reach (Fig. 3, top right panel): "From the little that I know about it, I can't afford to make the changes necessary to play my individual role in combatting climate change. The cost of living is already getting beyond the reach of the average Australian, and with extra taxes such as the Flood Levy and Carbon Tax possibly being introduced, the trickledown [sic] effect will make it less likely that I will have the money available to make a change" (AUS_NS Survey, April 2011).

The fourth thread was associated with information (Fig. 3, bottom right panel, red ellipse): "I can't prepare for something until I have all the details of what is exactly involved" (AUS_NS Survey, April 2011).

These four threads provide indicators for action in relation to those in the precontemplation stage.

1. Communicating with the general public, with real and tangible examples of how individuals are making a difference taking small and plausible steps; demonstrating how every country's part helps; acknowledging people who take action with formal, public recognition; and creating a sense of moral obligation to leading the world and acting responsibly for Australia's future could each allay the sense of impotence.

2. Denial may be difficult to address head-on, but perhaps it can be at least partially addressed through normalizing climate adaptive behaviors through the sorts of actions identified in point 1 .

3. Clear demonstrations of the usefulness of simple behavior changes and the sorts of communications outlined in point 1 could help precontemplation people shift to contemplation or action.

4. Information is clearly a double-edged sword, with many respondents signifying that their narratives were about people being overwhelmed with information. People need evidence that they can trust. This may not be from government or business, but when people see government and business acting, they will take notice. Many narratives noted that if business or government does not act, why should we? More than information, people seemed to be seeking evidence that those they value and trust are acting. Building information campaigns around what is being done by high-profile people and business and a clear sense of government solidarity could do much to galvanize the support of precontemplators.

\section{Contemplation stage: preparing for climate change}

Four threads were clearly discernible in the narratives of those who identified their experiences as being in the contemplation stage of adapting to climate change. The first thread related to the costs of adaptation being a hindrance and hence the need for appropriate government support (Fig. 4, top right panel): "It's all well and good if we all could afford to run on completely green energy in our homes, but it costs too much to set up initially. More government incentives are needed" (AUS_NS Survey, April 2011).

The second thread was associated with technology and the need for people to just get on with it (Fig. 4, top left panel): "I have changed all my lightglobes which was not hard, [sic] I have had a person come to my house to look at my situation and discuss the ways I can reduce my output. Consideration [will] be given to installing solar panels" (AUS_NS Survey, April 2011).

The third thread was associated with the recognition that everyone has a part to play and that small steps could make a big difference: "... it is up to communities, individuals and companies to take their own actions. No matter how small, they can make a difference and start to deliver a critical mass" (AUS_NS Survey, April 2011).

The final thread emerging from those in the contemplation phase related to a sense of trust that others would do their part and indignation when they do not: "I've seen individuals make changes in their lifestyles, their homes and their workplaces. But there is a perception that the problem is so big and the big corporations won't make changes. The feeling is that governments are scared of the big companies and won't make them change fast enough" (AUS_NS Survey, April 2011).

These four threads from those in the contemplation phase provide indicators for action to bring about shifting contemplators to action. 
1. The costs of adapting. Government in Australia has already done much to provide incentives to adopt low-carbon technologies. However, the costs appear to be high for many households. There is still much that government can do to demonstrate the benefits of shifting, such as simple costbenefit indicators and communicating the cost benefits of simple behaviors that do not require any capital outlay. The important thing seems to be to engage people in small acts that can then be developed.

2. Getting on with it. Addressing climate change may not be the only means to motivate people to shift to action; this thread calls on people to act because it is in their best interests and in the interests of society and the planet. Technologies are already available. What is needed is the motivation to start. Integrated campaigns from all levels of government to get people beyond talking and procrastinating and doing small things could pay big dividends through engaging people in action.

3. Small steps are possible and count. A number of respondents seemed to believe that the problem was far bigger than themselves and required government or big business to solve it. They felt there was nothing they could do to make a difference. Demonstrating that the small steps taken by each individual can have an enormous impact may be useful to shift this group to the action stage.

4. Trust in business and government. This is a big issue for many people. It requires an earnest commitment from government and business to do positive things and then to demonstrate these to the public as a sign of their commitment and action.

\section{Action stage: changing}

Three threads were evident in the narratives of those who identified their experiences of climate adaptation as being about changing. The first thread was associated with technology as assisting and money as hindering adaptation (Fig. 5, top left and top right panels): "I and others I am close to have changed their use of energy/power in their daily lives to decrease their footprint. This includes turning devices off where possible, installing fans to decrease $\mathrm{A} / \mathrm{C}$ use etc, [sic] I have recently purchased a new car. I chose a diesel small car with low energy consumption. I am currently installing $\mathrm{P} / \mathrm{V}$ cells to generate my own power and decrease my reliance on energy generated from fossil fuels that generate high carbon emissions" (AUS_NS Survey, April 2011).

A second thread observed in these narratives was associated with the importance of information and in particular clear and evidence-based information (Fig. 5, bottom right panel): "The community needs useful, easy to understand but not condescending, information" (DSE Survey, October and November 2010).

The third thread was associated with urgency, values, and a sense of justice (Fig. 5, bottom left panel): "It is also tru [sic] to say that it is a little hipocritical [sic] to be condemming [sic] dirty coal fired power stations whilst making money by selling coal to china [sic]" (AUS_NS Survey, April 2011).
Fig. 5. Narrative signifiers for action stage narratives $(\mathrm{n}=252)$. Top left, factors helping; top right, factors hindering; bottom left, extent that following played a role; bottom right, how important were the following.
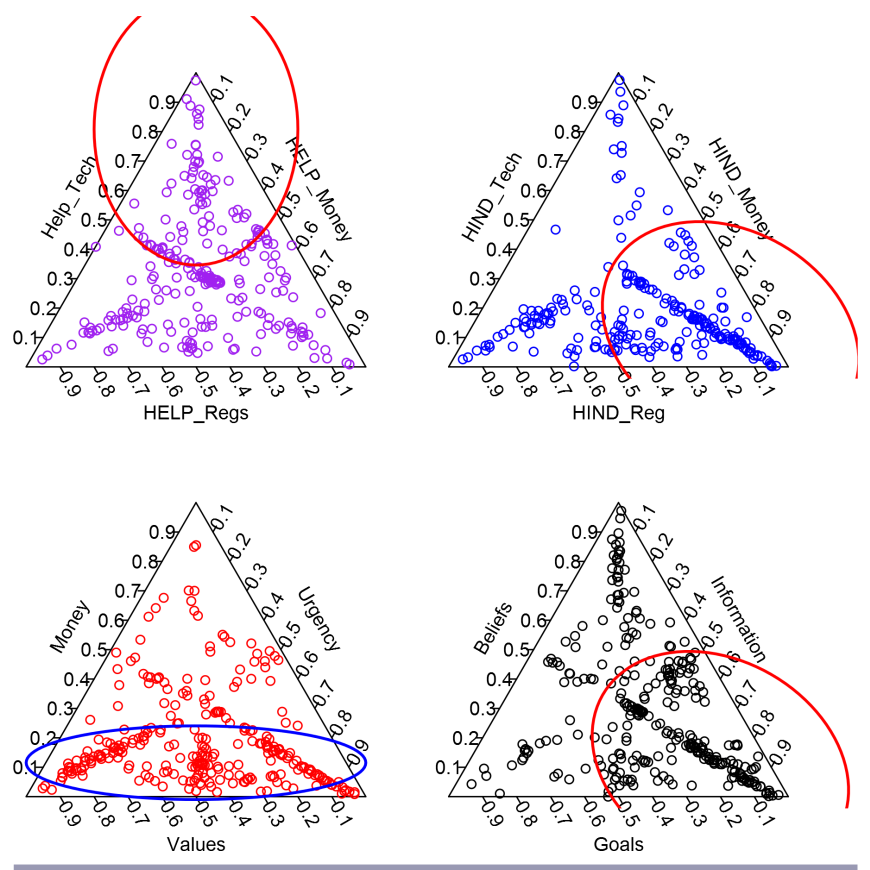

These three threads from those in the action phase provide indicators for action to consolidate bringing about shifting contemplators to action.

1. Technology. People are doing things, often small beginnings that can be strengthened and expanded. Creating networks of individuals or companies that are changing to share their experiences with particular technologies would expand the available information as well as help normalize the values associated with new ways of doing things. In addition, these networks would indicate tried and tested pathways for those wanting to take next steps that could help maintain the individual momentum plus provide indications of how an individual's progress can be expanded.

2. Information. Many people identified the desire for direct, practical information that moves beyond the "scientific mumbo-jumbo." Creating the networks described in point 1 should assist with this. In addition, it may be useful for key players to create information packages, e.g., integrated websites with downloadable guides, which compare different technological options for key changes and provide clear information on the relative costs and benefits of each pathway. These could be linked to change groups that are connected in the networks described in point 1.

3. Justice, values, and urgency. People need to believe that cheaters will be punished and that everyone will do their part. Promoting change through highlighting the achievements of individuals, companies, and government 
departments could create an ongoing acceptance of people and organizations doing their part and the sense of change as being "an essential part of life."

\section{Maintenance stage: magnifying and reinforcing change}

Two main threads were evident in the experiences described by those identifying their experiences as being associated with maintaining changes. A first thread was associated with the power of acting locally with many small steps that can lead to big results: "Small steps by many in the right direction can yield big results" (AUS_NS Survey, April 2011).

The second notable thread from respondents identifying their narratives with maintaining or reinforcing change was associated with the need to change public perceptions of government and business: "I seriously do'nt [sic] believe that major companies who are at the mercy of their shareholders have any intention of doing any more than they are made to do [sic] I can't think of one company which is a great example" (AUS_NS Survey, April 2011).

These two threads also suggest pathways for action.

1. The power of many small steps. Creating the networks of changers suggested in point 1 of the action phase activity set would help identify the importance of small steps and provide reinforcing relationships. Stimulating the creation of neighborhood and citywide change groups could provide the community support for change maintenance and expansion.

2. Trust in government and business to do their part. There is a clear distrust of government and business among respondents. Government and business themselves need to address these perceptions through highlighting the many positive things that companies and government are doing. Associations such as the Business Council of Australia and the Public Service Commission of the Australian Commonwealth government need to take steps to address the perception of mistrust that pervades certain sections of society in relation to issues such as climate change. Business and government are both doing a great deal, but unfortunately, people recall the few high-profile negative news stories. A consistent and positive framing of issues that highlights what is being done with clear examples of companies and government departments that are championing action would be an important step forward.

\section{SUMMARY AND CONCLUSIONS}

\section{Content}

Respondents identifying their experiences as being in the precontemplation stage believed that the individuals or groups in their responses were less able to make a difference than did those in the contemplation, action, or maintenance stages: consistent with the predictions of SOC model theory, efficacy does appear to be associated with taking action on climate change. Across all SOC, respondents identified money or the financial costs of changing as being the greatest barrier. This trend was particularly noticeable among the contemplators. Again, this is consistent with SOC model predictions that contemplators will be weighing the pros and cons, i.e., costs and benefits, of the change. For the most part, technology was seen as an important aid to adaptation, with the technologies that were needed for individuals to adapt already available.

Information, in the form of clear, trustworthy, and exemplar information, was important across all SOC groups. Of interest was the strong role of beliefs among the experiences of contemplators, with information playing a more dominant role with the other groups.

Values and urgency were identified as being more important than money by all groups, suggesting that adaptation was more about individual or group values than the financial costs that had been identified as an important barrier to change. The implication is that when appropriate social values are in place, the money to achieve the goals will be found. The plausibility of the pathways to action that we have suggested for SOC groups could be tested and refined with representatives from community, business, and government at the local level.

\section{Contributions to acting in relation to complex problems}

We started by questioning how, in complex problem situations such as adaptation to climate change, we could analyze conversations and experiences across multiple perspectives without imposing our own frames of reference and, through so doing, identify appropriate intervention points. We have demonstrated one approach to doing this, based on SenseMaker. Using the SOC, i.e., transtheoretical, model as an analytical framework, we have identified patterns in the factors associated with enabling or constraining adaptation to climate change that would inform action by our hypothetical social actor, i.e., policy maker or concerned social group, to achieve improved adaptation to climate change. We have shown how people in different stages of their relationship to adapting to climate change experience and talk about adaptation in different ways and how we could use these descriptions to identify specific intervention strategies for each of these groups.

The SOC perspective we have adopted is one of many possible frameworks that could be used to examine the problem of adaptation to climate change. With its roots in the treatment of addiction, the SOC model can serve to remind us of the strength of entrenched patterns of action as influences on what people do: to lesser or greater extents, we are all "addicted" to our current lifestyles. Altering lifestyle elements to adapt to climate change is likely to be as difficult an undertaking as is altering any other addictive behavior. However, the model also suggests what interventions might be most applicable for each stage: contemplators, for example, are aware of the problem but have not yet decided to act; they are weighing the pros and cons of action and, in a way, need to let go of those parts of their identity that are linked to behaviors that need to change and start building identity links to new behaviors. They are thus likely to respond to information, to assist them in making the choices clearer and in weighing the options, and also to examples of others, perhaps from their social group, who can demonstrate to them new identity elements (Prochaska and DiClemente 1986, Prochaska et al. 1992).

Although the SOC model recognizes the importance of the social context in which individuals seek to alter their behaviors, e.g., it may be difficult for people to maintain a new behavior if all their friends continue to support the old behavior, it remains a model 
oriented to individual behavior change. Climate change may be more of a social phenomenon than drug addiction in the sense that individuals are seeking to shift away from socially "normal" behavior, e.g., reducing energy use, whereas drug addicts would be seeking to shift toward socially "normal" behavior, i.e. not taking drugs. We would thus expect a greater need for working with social change processes in relation to climate change than the SOC model might suggest. In particular, the data presented demonstrate the social structures and processes that maintain the "normality" of particular behaviors, e.g., when government and industry are not seen to be doing anything, this suggests to individuals that they do not need to do anything.

Advocates of the SOC model suggest that the SOC and the process of change associated with each stage may be consistent across change behaviors for different lifestyle elements (Rosen 2000). Our analyses suggest this is the case: the SenseMaker data do not focus on specific behaviors or practices but range across a very broad spectrum, from switching off lights through changing lightbulbs to refitting a business or home. Across this broad spectrum, we were still able to detect clear patterns of associations among factors that were consistent for specific SOC.

Our data also indicate, however, that boundaries between the SOC in relation to action on climate change are not crisp: people can be in several stages at once; adaptation is not an all-or-nothing situation. This means that support for movement through the SOC may need to be very carefully targeted if, for example, people are contemplating solar while at the same time maintaining reduced energy consumption through switching lights off.

\section{Process and tools}

SenseMaker provided a powerful tool for collecting the type of rich data that was discussed as being important in the Introduction. Climate change is complex, and the diverse experiences people have of climate change form complex patterns that require us to be able to examine these diverse experiences from different perspectives and using different methods. Being able to readily navigate between patterns in the signifiers and the narratives themselves enabled us to explore and check meanings and interpretations that emerged from the analyses associated with the SOC model. Because SenseMaker enables respondents to interpret their own narrative, we have been able to investigate large numbers of experiences with less concern for the imposition of our own biases than we would have were we coding these narratives ourselves.

This approach of respondent-interpreted micronarratives offers a potentially important addition to the toolbox of mixed methods researchers and practitioners. The instrument and data are inherently mixed and enable the user to rapidly and easily move between the quantitative and qualitative elements of the data, and the SenseMaker software suite provides a number of useful tools for the examination of patterns in the data.

Although SenseMaker provides notable flexibility and utility, there are some aspects of it that are frustrating and less useful. It is very difficult to aggregate the data across groups to provide aggregated results. The statistical analysis processes within SenseMaker (V2.5) were weak to nonexistent; for example, the ttest routine did not work, and we had to perform all the statistical tests that we have presented outside of SenseMaker. SenseMaker also does not provide any capability to analyze the narratives themselves: they may be searched and examined in relation to the signifiers, but the narratives themselves are not analyzed.

Although rich and highly informative, the data and approach we have used could be significantly improved as follows: We do not have data that could inform us about transition probabilities across the SOC. However, the SOC model does alluringly suggest that these could be generated through repeated surveys of cohorts (see, e.g., Carbonari et al. 1999) and hence provide indications of the efficacy of targeted interventions. Our samples were samples of convenience and were unlikely to be representative of specific target populations. As a consequence, our results should be treated as being indicative rather than confirmatory. Finally, resolution of, or working through, complex problems requires sensitivity to different perspectives. Although the SenseMaker data enable analyses from different perspectives, we have adopted only the perspective of those involved in different SOC. We could, for example, have looked at SOC from the perspective of academics, from that of government employees, and from that of the general public. We have really only scratched the surface of the analytical potential of this data set, as other articles in the special feature demonstrate.

Responses to this article can be read online at: http://www.ecologyandsociety.org/issues/responses. $\mathrm{php} / 7410$

\section{Acknowledgments:}

The authors gratefully acknowledge the support and assistance of staff and students from the University of the Sunshine Coast in relation to collecting data at the NCCARF conference. This research was part of the South East Queensland Climate Adaptation Research Initiative, a partnership between the Queensland and Australian governments, the CSIRO Climate Adaptation National Research Flagship, Griffith University, University of the Sunshine Coast, and University of Queensland. The initiative aimed to provide research knowledge to enable the region to adapt and prepare for the impacts of climate change. Additional funding was provided by CSIRO's Climate Adaptation Flagship. We are very grateful for the suggestions of two anonymous reviewers whose comments have helped improve the paper. Thanks to Iain Walker whose timely suggestions and encouragement helped get the paper over the last hurdles. We would also like to acknowledge the truly remarkable open source contributions that the $R$ user community has made to our ability to analyze these data: we frequently availed ourselves of, and found enormously helpful, the generous contributions of code, packages, and answers to myriad questions from the user community. Thank you!

\section{LITERATURE CITED}

Ajzen, I. 1996. The directive influence of attitudes on behavior. Pages 385-403 in P. M. Gollwitzer and J. A. Bargh, editors. Psychology of action. Guilford, New York, New York, USA.

Armitage, C. J. 2009. Is there utility in the transtheoretical model? British Journal of Health Psychology 14:195-210. http://dx.doi. org/10.1348/135910708X368991 
Australian Public Services Commission. 2007a. The changing behaviour. A public policy perspective. Australian Public Services Commission, Canberra, Australian Capital Territory, Australia.

Australian Public Services Commission. 2007b. Tackling wicked problems. A public policy perspective. Australian Public Services Commission, Canberra, Australian Capital Territory, Australia.

Bandura, A. 1986. Social foundations of thought and action: a social cognitive theory. Prentice-Hall, Englewood Cliffs, New Jersey, USA.

Barthes, R. 1977. Image, music, text. Translated by Stephen Heath. Fontana, London, UK.

Bazeley, P. 2012. Integrative analysis strategies for mixed data sources. American Behavioral Scientist 56:814-828. http://dx.doi. org/10.1177/0002764211426330

Bovens, M. A. P., and P. 't Hart. 1996. Understanding policy fiascoes. Transaction, New Brunswick, New Jersey, USA.

Brown, V. A., J. A. Harris, and J. Y. Russell. 2010. Tackling wicked problems through the transdisciplinary imagination. Earthscan, London, UK.

Burnham, K. P., and D. R. Anderson. 2002. Model selection and multimodel inference: a practical information-theoretic approach. Springer, New York, New York, USA.

Cacioppo, J. T., and R. E. Petty. 1982. The need for cognition. Journal of Personality and Social Psychology 42:116-131. http:// dx.doi.org/10.1037/0022-3514.42.1.116

Cacioppo, J. T., R. E. Petty, J. A. Feinstein, and W. B. G. Jarvis. 1996. Dispositional differences in cognitive motivation: the life and times of individuals varying in need for cognition. Psychological Bulletin 119:197-253. http://dx.doi. org/10.1037/0033-2909.119.2.197

Carbonari, J. P., C. C. DiClemente, and K. B. Sewell. 1999. Stage transitions and the transtheoretical "stages of change" model of smoking cessation. Swiss Journal of Psychology 58:134-144. http://dx.doi.org/10.1024//1421-0185.58.2.134

Clandinin, D. J., and F. M. Connelly. 2000. Narrative inquiry: experience and story in qualitative research. First edition. JosseyBass, San Francisco, California, USA.

Cognitive Edge. 2010. SenseMaker Suite. Cognitive Edge, Singapore.

Czarniawska, B. 1997. A four times told tale: combining narrative and scientific knowledge in organization studies. Organization 4:7-30. http://dx.doi.org/10.1177/135050849741002

Czarniawska, B. 2002. Narrative, interviews and organizations. Pages 733-749 in J. F. Gubrium and J. A. Holstein, editors. Handbook of interview research. Sage, London, UK. http://dx.doi. org/10.4135/9781412973588.d42

DiClemente, C. C., and J. O. Prochaska. 1982. Self-change and therapy change of smoking behavior: a comparison of processes of change in cessation and maintenance. Addictive Behaviors 7:133-142. http://dx.doi.org/10.1016/0306-4603(82)90038-7

Edelman, M. 1988. Constructing the political spectacle. University of Chicago Press, Chicago, Illinois, USA.
Fielding, N. G. 2012. Triangulation and mixed methods designs: data integration with new research technologies. Journal of Mixed Methods Research 6:124-136. http://dx.doi.org/10.1177/1558689812437101

Franzosi, R. 1998. Narrative analysis - or why (and how) sociologists should be interested in narrative. Annual Review of Sociology 24:517-554. http://dx.doi.org/10.1146/annurev.soc.24.1.517

Funtowicz, S. O., and J. R. Ravetz. 1994. Uncertainty, complexity and post-normal science. Environmental Toxicology and Chemistry 13:1881-1885. http://dx.doi.org/10.1002/etc.5620131203

Gelman, A., J. B. Carlin, H. S. Stern, and D. B. Rubin. 1995. Bayesian data analysis. First edition. Chapman and Hall, London, UK.

Greene, J. C. 2008. Is mixed methods social inquiry a distinctive methodology? Journal of Mixed Methods Research 2:7-22. http:// dx.doi.org/10.1177/1558689807309969

Healy, S. 2011. Post-normal science in postnormal times. Futures 43:202-208. http://dx.doi.org/10.1016/j.futures.2010.10.009

Johnson, R. B., and A. J. Onwuegbuzie. 2004. Mixed methods research: a research paradigm whose time has come. Educational Researcher 33:14-26. http://dx.doi.org/10.3102/0013189X033007014

Kramp, M. K. 2004. Exploring life and experience through narrative inquiry. Pages 103-122 in K. deMarrais and S. D. Lapan, editors. Foundations for research: methods of inquiry in education and the social sciences. Lawrence Erlbaum, Mahwah, New Jersey, USA.

Kurtz, C. F., and D. J. Snowden. 2003. The new dynamics of strategy: sense-making in a complex and complicated world. IBM Systems Journal 42:462-483. http://dx.doi.org/10.1147/sj.423.0462

Lazarus, R. J. 2009. Super wicked problems and climate change: restraining the present to liberate the future. Cornell Law Review 94:1153-1233.

Levin, K., B. Cashore, S. Bernstein, and G. Auld. 2012. Overcoming the tragedy of super wicked problems: constraining our future selves to ameliorate global climate change. Policy Sciences 45:123-152. http://dx.doi.org/10.1007/s11077-012-9151-0

Lorenzoni, I., and M. Hulme. 2009. Believing is seeing: laypeople's views of future socio-economic and climate change in England and in Italy. Public Understanding of Science 18:383-400. http:// dx.doi.org/10.1177/0963662508089540

Lorenzoni, I., A. Leiserowitz, M. de Franca Doria, W. Poortinga, and N. F. Pidgeon. 2006. Cross-national comparisons of image associations with "global warming" and "climate change" among laypeople in the United States of America and Great Britain. Journal of Risk Research 9:265-281. http://dx.doi. org/10.1080/13669870600613658

Lorenzoni, I., and N. F. Pidgeon. 2006. Public views on climate change: European and USA perspectives. Climatic Change 77:73-95. http://dx.doi.org/10.1007/s10584-006-9072-z

Manson, S. M. 2001. Simplifying complexity: a review of complexity theory. Geoforum 32:405-414. http://dx.doi. org/10.1016/S0016-7185(00)00035-X 
Mertens, D. M. 2010. Research and evaluation in education and psychology: integrating diversity with quantitative, qualitative, and mixed methods. Third edition. Sage, Los Angeles, California, USA.

Milne, K. M. G. 2015. Can sense-making tools inform adaptation policy? A practitioner's perspective. Ecology and Society 20(1):66. http://dx.doi.org/10.5751/ES-06791-200166

Noble, D., and T. Bennett. 2007. Climate change. A wicked problem (part II). Municipal World 117:57-59.

Oreskes, N., and M. Conway. 2010. Merchants of doubt. How a handful of scientists obscured the truth on issues from tobacco smoke to global warming. Bloomsbury, New York, New York, USA.

Pierce, D. W., T. P. Barnett, B. D. Santer, and P. J. Gleckler. 2009. Selecting global climate models for regional climate change studies. Proceedings of the National Academy of Sciences of the United States of America 106:8441-8446. http://dx.doi. org/10.1073/pnas.0900094106

Prochaska, J. O., and C. C. DiClemente. 1986. Toward a comprehensive model of change. Pages 3-27 in W. R. Miller and N. Heather, editors. Treating addictive behaviors: processes of change. Plenum, New York, New York, USA. http://dx.doi. org/10.1007/978-1-4613-2191-0 1

Prochaska, J. O., C. C. DiClemente, and J. C. Norcross. 1992. In search of how people change: applications to addictive behaviors. American Psychology 47:1102-1114. http://dx.doi. org/10.1037/0003-066X.47.9.1102

Räisänen, J., and T. N. Palmer. 2001. A probability and decisionmodel analysis of a multimodel ensemble of climate change simulations. Journal of Climate 14:3212-3226. http://dx.doi. org/10.1175/1520-0442(2001)014<3212:APADMA>2.0.CO;2

Ravetz, J. 2004. The post-normal science of precaution. Futures 36:347-357. http://dx.doi.org/10.1016/S0016-3287(03)00160-5

Reichler, T., and J. Kim. 2008. How well do coupled models simulate today's climate? Bulletin of the American Meteorological Society 89:303-311. http://dx.doi.org/10.1175/BAMS-89-3-303

Rittel, H. W. J., and M. M. Webber. 1973. Dilemmas in a general theory of planning. Policy Sciences 4:155-169. http://dx.doi. org/10.1007/BF01405730

Rosen, C. S. 2000. Is the sequencing of change processes by stage consistent across health problems? A meta-analysis. Health Psychology 19:593-604. http://dx.doi.org/10.1037/0278-6133.19.6.593

Sandelowski, M. 2014. Unmixing mixed-methods research. Research in Nursing \& Health 37:3-8. http://dx.doi.org/10.1002/ nur. 21570

Snowden, D. 2002. Complex acts of knowing: paradox and descriptive self-awareness. Journal of Knowledge Management 6:100-111. http://dx.doi.org/10.1108/13673270210424639

Snowden, D. J., and M. E. Boone. 2007. A leader's framework for decision making. Harvard Business Review 85:68-76.

Sutton, S. 2001. Back to the drawing board? A review of applications of the transtheoretical model to substance use.
Addiction 96:175-186. http://dx.doi.org/10.1046/j.1360-0443.2001.96117513.x

Tashakkori, A., and C. Teddlie. 2003. Handbook of mixedmethods in social \& behavioral research. Sage, Thousand Oaks, California, USA.

Tashakkori, A., and C. Teddlie. 2010. Sage handbook of mixed methods in social \& behavioral research. Sage, Los Angeles, California, USA.

Teddlie, C., and A. Tashakkori. 2009. Foundations of mixed methods research: integrating quantitative and qualitative approaches in the social and behavioral sciences. Sage, Los Angeles, California, USA.

Wagner, W., and N. Hayes. 2005. Everyday discourse and common sense. The theory of social representations. Palgrave, New York, New York, USA.

Webster, D. M., and A. W. Kruglanski. 1994. Individualdifferences in need for cognitive closure. Journal of Personality and Social Psychology 67:1049-1062. http://dx.doi. org/10.1037/0022-3514.67.6.1049

Weick, K. E. 1995. Sensemaking in organizations. Sage, Thousand Oaks, California, USA. 
Appendix 1. Overview of Bayesian data modelling.

In this brief appendix we describe the methods and present additional detailed results of the Markov chain Monte Carlo modelling used for estimating differences in mean efficacy score for survey responses in which respondents identified their micro-narrative as being associated with particular stages of change (SOC).

In the survey respondents were asked to use a polarity scale that ranged from 0 to 100 and measured efficacy to identify how able to make a difference individuals or groups felt in the response they related. The specific question was:

The individuals or groups in my response were:

Unable to make a difference. Overwhelmed by the opportunities to have an impact.

The resulting efficacy scores were not normally distributed (Figure A1.1), they were also bound between 0 and 100 and had an implicit ideal state in the middle of the score range (i.e. 50). Standard Gaussian assumptions would therefore not be appropriate for these data.

We elected to use a Beta distribution to describe these data given the beta distribution is bound between 0 and 1 and because of its great flexibility in terms of the range of distributional shapes it can represent with different values of its two parameters $(\alpha, \beta)$ (other polarity distributions in the data set exhibited even more extreme distributional forms than those shown in Figure A1.1).

Preliminary investigation of the data indicated that by using a log transformation and then dividing the result by 5 (to render the results between 0 and 1 ) the data were more reliably modelled by the Beta distribution.

Using the approach of Gelman et al (1995) we developed a Bayesian hierarchical model to estimate the differences in mean efficacy values across the four SOC. Using R's (R Core Team 2013) capacity to link to JAGS (Just Another Gibbs Sampler)(Plummer 2003, Su and Yajima 2014) we developed a model to estimate the alpha and beta parameters of the (beta) distribution of efficacy scores for each SOC data set (see note 1 below). The model was set up as a hierarchical Bayesian model with three stochastic nodes for estimating mean efficacy for each SOC: the alpha and beta parameters of the Beta distribution (with both of these parameters being normally distributed) and the efficacy distribution itself which was a beta distribution. Following Gelman et al $(1995, \mathrm{p} 477)$ the mean of the efficacy distribution was calculated as: alpha/(alpha + beta) and the mode was estimated as (alpha 1) / (alpha + beta -2$)$. Once the alpha and beta parameters were estimated they were used to estimate the mean and mode of the distribution. Differences in means were estimated by subtracting, for each iteration, the value of $m u$ (i.e. the mean) of each SOC from the mu's of the remaining SOC. Estimates presented in Figure $1 \mathrm{a}$ and $1 \mathrm{~b}$ of the main paper reflect the samples taken from the posterior distributions. 


\section{Pre-contemplation}

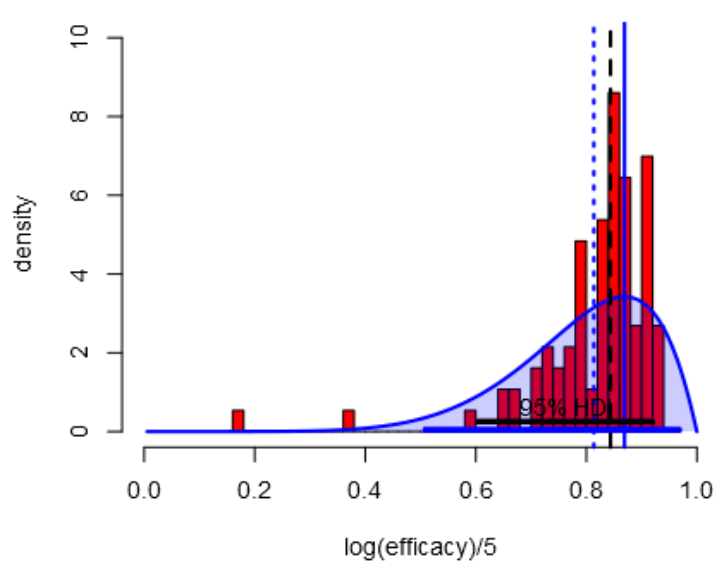

Action

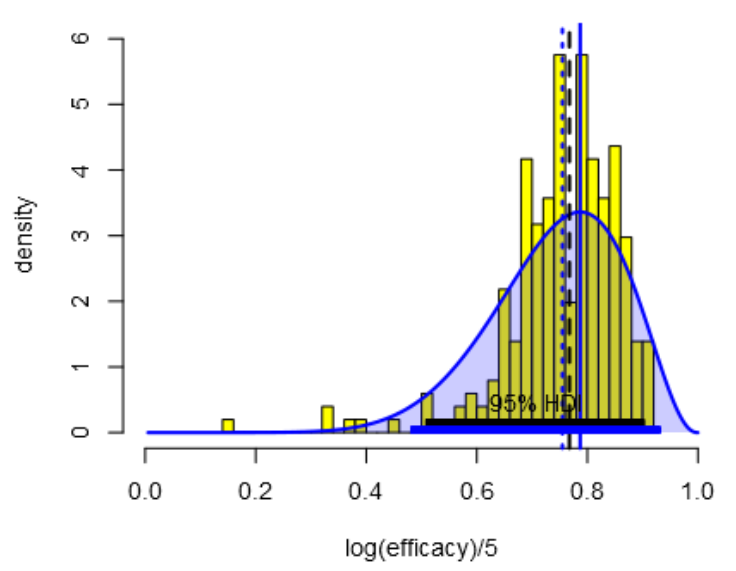

\section{Contemplation}

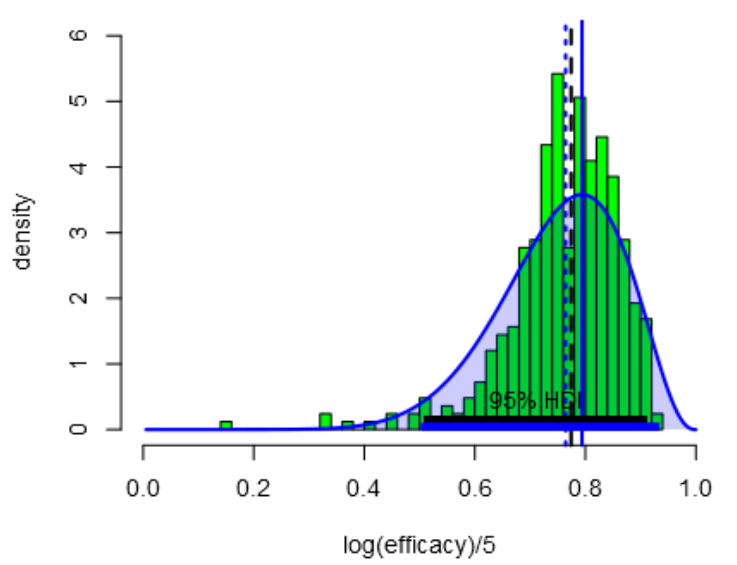

\section{Maintenance}

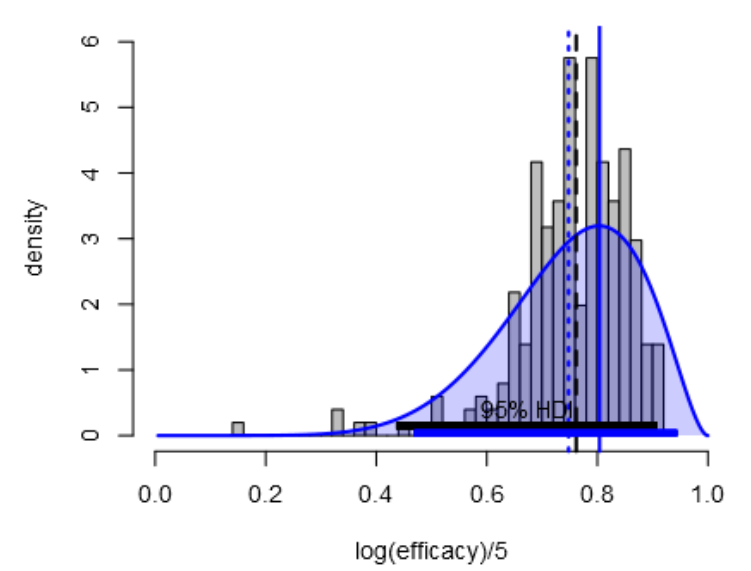

Figure A1.1. Probability density plots of the transformed $(y=\log ($ efficacy)/5) efficacy data for each SOC. The shaded curves are the posteriors of the estimated Beta distributions for each SOC. The histograms show the distribution of the transformed data. The solid vertical line is the mode for the Beta distribution. The black dashed vertical line is the median of the data. The dotted blue vertical line is the median of the Beta distribution. The 95\% HDI bars at the bottom of each plot identify $95 \%$ of the probability mass: the blue bar for the Beta distribution and the black bar for the data associated with each plot.

In each simulation 3 chains were initialised and run for 50,000 iterations. The first 10,000 iterations were discarded. From the remaining 40,000 every tenth result was saved and used for subsequent analyses. For each beta distribution the priors on alpha and beta were initialised at values of 3 and 2 respectively to achieve a prior distribution with a slight negative skew.

The resulting three chains were examined for convergence using density plots of the estimates of each parameter, including the means, and plots of running means for each parameter for each chain. Convergence was excellent for all parameters. The results were also examined for autocorrelation which was negligible over all lags.

Summary results for the model are presented in Table A1.1. The model captured the data distributions reasonably well (Figure A1.1) although in most cases the data distributions were more peaked than the beta although this was only really marked in the pre-contemplation stage (Figure A1.1). 
Table A1.1. Summary of the MCMC simulations of the parameters of the Beta distributions (alpha_hyper and beta_hyper) and the mean $(\mathrm{mu})$ and mode of each distribution across SOC. For each parameter, n.eff is a crude measure of effective sample size, and Rhat is the potential scale reduction factor (at convergence, Rhat $=1$ ). Suffix ".i" was used for parameters associated with the pre-contemplation stage; suffix ".r" was used for the contemplation / preparation stage; suffix ".c" for the action stage; and suffix ". $m$ " for the maintenance stage.

\begin{tabular}{|c|c|c|c|c|c|c|c|c|c|c|}
\hline $\begin{array}{l}\text { Parameter } \\
\text { group }\end{array}$ & Parameter & mean & stdev & $2.5 \%$ & $25 \%$ & $50 \%$ & $75 \%$ & $98 \%$ & Rhat & n.eff \\
\hline \multirow{8}{*}{$\begin{array}{l}\text { Parameters of } \\
\text { Beta Distributions }\end{array}$} & alpha.hyper.c & 9.464 & 0.634 & 8.232 & 9.046 & 9.455 & 9.892 & 10.728 & 1.001 & 11000 \\
\hline & alpha.hyper.i & 7.754 & 0.752 & 6.299 & 7.249 & 7.741 & 8.252 & 9.257 & 1.001 & 12000 \\
\hline & alpha.hyper.m & 8.278 & 0.652 & 7.034 & 7.828 & 8.266 & 8.711 & 9.584 & 1.001 & 4300 \\
\hline & alpha.hyper.r & 10.575 & 0.588 & 9.448 & 10.169 & 10.564 & 10.973 & 11.739 & 1.001 & 12000 \\
\hline & beta.hyper.c & 3.292 & 0.223 & 2.861 & 3.141 & 3.288 & 3.441 & 3.735 & 1.001 & 12000 \\
\hline & beta.hyper.i & 2.023 & 0.205 & 1.634 & 1.884 & 2.018 & 2.156 & 2.44 & 1.001 & 12000 \\
\hline & beta.hyper.m & 2.782 & 0.221 & 2.355 & 2.633 & 2.777 & 2.93 & 3.228 & 1.002 & 3000 \\
\hline & beta.hyper.r & 3.488 & 0.192 & 3.121 & 3.358 & 3.489 & 3.614 & 3.879 & 1.001 & 12000 \\
\hline \multirow{4}{*}{$\begin{array}{c}\text { Modes of } \\
\text { distributions }\end{array}$} & mode.c & 0.787 & 0.009 & 0.77 & 0.781 & 0.787 & 0.793 & 0.805 & 1.001 & 12000 \\
\hline & mode.i & 0.869 & 0.016 & 0.838 & 0.858 & 0.869 & 0.88 & 0.903 & 1.001 & 12000 \\
\hline & mode.m & 0.804 & 0.012 & 0.78 & 0.796 & 0.803 & 0.811 & 0.827 & 1.001 & 5700 \\
\hline & mode.r & 0.794 & 0.006 & 0.781 & 0.79 & 0.794 & 0.798 & 0.806 & 1.001 & 12000 \\
\hline \multirow{4}{*}{$\begin{array}{c}\text { Means of } \\
\text { distributions }\end{array}$} & mu.c & 0.742 & 0.007 & 0.727 & 0.737 & 0.742 & 0.747 & 0.756 & 1.001 & 12000 \\
\hline & mu.i & 0.793 & 0.012 & 0.769 & 0.785 & 0.793 & 0.801 & 0.816 & 1.001 & 12000 \\
\hline & mu.m & 0.748 & 0.009 & 0.73 & 0.742 & 0.749 & 0.755 & 0.766 & 1.001 & 12000 \\
\hline & mu.r & 0.752 & 0.005 & 0.741 & 0.748 & 0.752 & 0.756 & 0.762 & 1.001 & 12000 \\
\hline Model fit & deviance & -1670.1 & 9.544 & -1687.1 & -1676.8 & -1670.6 & -1663.9 & -1650 & 1.001 & 9600 \\
\hline
\end{tabular}

Notes

1. As the instrument permitted respondents to select more than one SOC there is some overlap in the data sets. Those that told of experiences associated with the precontemplation phase did not overlap with any of the other stages.

\section{References cited}

Gelman, A., J. B. Carlin, H. S. Stern, and D. B. Rubin. 1995. Bayesian data analysis. First edition. Chapman and Hall, London, UK.

Plummer, M. 2003. JAGS: A program for analysis of Bayesian graphical models using Gibbs sampling. Pages 20-22 in 3rd International Workshop on Distributed Statistical Computing, Vienna, Austria.

R Core Team. 2013. R: A language and environment for statistical computing. R Foundation for Statistical Computing, Vienna, Austria.

Su, Y.-S., and M. Yajima. 2014. R2jags: A Package for Running jags from R. 